Original Contribution

\title{
SENSORY BASIS OF THE VISUAL PERCEPTION OF ORAL SPEECH IN CHILDREN WITH HEARING DISORDERS
}

\author{
D. Georgieva* \\ Faculty of Education, Trakia University, Stara Zagora, Bulgaria
}

\begin{abstract}
Visual perception of spoken language is an alternative model that ensures the successful communication of children with hearing impairment. This inherently complex process is based on the predominant involvement of the visual modality. The optical characteristics of the sounds and the prosodial components and their perception in the composition of words and sentences are based on an extensive sensory foundation where in children with a high degree of hearing loss the visual modality is of leading importance. Although vision has the leading role in the visual perception of the speech of deaf people, the sensory basis is generally regarded as including the whole preserved sensitivity.
\end{abstract}

Key words: children with hearing disorders, visual perception of speech, sensory-based, sounds, prosodial components

\section{INTRODUCTION}

Visual processing or "speech reading" is a priority activity directed toward people with impaired auditory modality. Obviously, the presence of hearing impairment requires acquisition of alternative means of decoding interlocutor's speech.

Speech, viewed in its communicative function, is presented as the most commonly applied verbal communication model which suggests perception of speech information (hearing) and its transmission (speech production). Undoubtedly, to different extents, impaired hearing creates barriers related to oral language communication and its formation in children.

At the same time, in full loss of hearing condition are preserved perception compensatory mechanisms, understanding and speech development (in its oral version) which are determined by the intact functions of the visual, tactile and movement modalities. And "total deafness" is not a very common phenomenon. The predominant part of people with heavy hearing deprivation retains minimum auditory

*Correspondence to: Diyana Georgieva, PhD student in the Faculty of Education at Trakia University, Stara Zagora resources which provide, to some extent, perception and understanding of speech.

Leading position in oral information perception and deciphering is attributed to the visual sensory channel.

Visual perception and understanding of speech is a complex process and for its acquisition and successful realization is required development and application of therapeutic strategies which include special training in "lip reading" $(1,2) /$ registering on lips and "speechreading" $(3,4)$. The differentiation of the suggested terminological models is detailed in the following content (5):

"Lip reading" is interpreted as speech perception and focusing attention and memory on the visible movements of articulatory organs of the speaker. A large part of these movements are inaccessible to sight which determines the limited character of visual processing. Often "lip reading" is compared to unreadable handwriting perception or half erased written structures (6, 7). An additional complication to visual perception is generated by the fact that "the written" is not in static position. The person who perceives the written symbols has the opportunity to stop or to go back to a fixed in previous position written structure, in which the 
graphemes can be "read" with difficulty. While in registering on lips the oral images of sounds are carried out in dynamic movements in time axis.

"Speechreading" and decoded through sight speech is viewed in a broader aspect. It includes focusing attention not only on articulatory poses, but on the total whole of nonverbal instruments of communicative act realization as well.

Therefore, the sensory base of visual processing is presented not only by phonetic elements of speech, but by the total whole of information synchronization containing verbal and nonverbal signals.

\section{Phonetic elements of speech}

Material substance of language through which certain semantic meaning is conveyed is presented by its phonemic (phonological) level. Pertaining to phonetic elements of speech, the main elements of speech comprising this level are phonemes, word stress, and intonation.

The phoneme is a sound, a sound type, whose main function is to differentiate the material form of words. Based on its articulation and acoustics, the phoneme as a sound possesses a particular number of phonological attributes (8).

Acoustic properties of speech sounds are subject to some changes depending on their phonotactics (their ability to combine between themselves). As a result of phoneme's valence and combinatorics (the position and surroundings of adjacent sounds within a word) are formed different phoneme versions. But the versions of every phoneme in various phonetic conditions are opposed to each other as a rule.

To the acoustic differences between speech sounds correspond certain articulatory ones, which are objects of visual perception.

\section{General classification of vowels}

The sounds belong to the Bulgarian phonetic system, therefore they are written in the Cyrillic alphabet.

Vowels, also called vocals, comprise a significantly smaller group compared to consonants. Depending on the frequency of use the first group is characterized by higher indices. According to data from V. Katsarska's research vowels in native language occur in about $43,2 \%$ of the spoken sounds in flow of speech (9).

They represent a homogenous group in acoustic aspect (their main tone is free from noises).
Vowels, especially, [a], [o], [y], possess a huge acoustic power. This is manifested most audibly when the mentioned vowels are carriers of phrasal stress in words. The loudness of vocals [е] and Ги] sounding is significantly weaker.

General vocals attribute is vibration of vocal folds, which is a condition for airstream voicing going from lungs in exhaling phase of the general breathing action.

Depending on the place of vowels' articulation they are divided into front vowels [a], [ъ], [o], [y].

The localization of the narrowing is determined mainly by the position of the tongue, lips, velum and size of the jaw angle, which depends on the height of the mandible. The height of tongue elevation towards the palate is also a differentiating feature and places vocals in three subgroups - narrow [и], [ъ], middle [е], [о], [ъ] and wide [a].

The next attribute is extremely important as well - motion of lips. In articulation of vowels [o] and $[y]$ they participate actively, significantly approaching each other and moving forth in a circled pose "trunk" because of what they are called labial. In [a] and [ъ] lips are in a neutral pose, and in [е] and Ги] they are drawn in pose "smile". Vowels [а], [ъ], [е] and [и] are presented as nonlabial in phonetics literature.

\section{Vowel sounds and visual perception}

In specialized literature the perception of sounds' optical characteristics and the other phonetic elements of speech are viewed as a perception of articulatory organs which are related to their production.

Own studies with the aim to define the sensory base of visual processing confirm the fact that from the two main sound groups (vowels and consonants), which are in position of sharp contrast in their phonemic features, the priority position of visual perception has the group of vocals. From the vowel group the sounds [a], [o], [y] are well visualized and comparatively less successfully - [и] and [е] and the least percentage of success has the vowel [ъ].

Sounds from the consonants' group placed in combination with vowels define in different way their visualization.

The most positive impact in this aspect is observed in sound [a], situated in preceding 
position. For the rest of the vowels and particularly for the vocal [y] this statement is negative. The reason for this is that in the natural flow of speech there is a phenomenon called coarticulation. Speech organs prepare to articulate the following sound not after finalizing the pronunciation of the preceding one, but in the very process of the articulation. And thus in producing of consonants in position after vocal [y] lips in the process of the very articulation of this vowel sound are circled forward and right in this configuration "disguise" or change their optical characteristics. The place of $[y]$ in relation to consonants defines the realization of their visual perception.

Phonological attributes of vocal [a] are of advantage to the optical image of the preceding consonant and optimize the perception of the visual characteristics of consonant sounds regardless of combinatorial conditions.

\section{General classification of consonants}

To vowel sounds is opposed a large group of consonants, which are differentiated according to bigger number of distinguishing features. These not only divide them into a relatively independent group, but also differentiate them within those groups.

In consonants production vocal folds not always vibrate, which separates them in two groups. Thus phonemes are divided in: voiced - [б, б'], [в, в'], [г, г'], [д, д’], [3, з'], й], [л, л'], [м, м'], [н, н'], [p, p'], [дз, дз'], [ж], [дж] and voiceless - [к, к'], [ח, п’], [c, с'], [т, т'], [ф, ф’], [x, х'], [ц, ц'], [ч], [ш].

Depending on the palatality attribute (softening) the consonants fall into two groups. Palatalization is a result from slight elevation of the middle part of the tongue toward palate. The place of articulation which indicates the more specific part of vocal tract separates the group of consonants in labial (bilabial and labiodental), alveolar (alveodental and alveolar), prepalataland and velar.

Labial consonants are a group of sounds in which pronunciation is realized by or through participation of lips (bilabial: [ח, П’], [б, б'], [м, $\left.\mathrm{M}^{\prime}\right]$ ) or by upper incisors and lower lip (labiodental: [ф, ф'], [в, в']).

Alveolar consonants fall into: alveodental $-[\mathrm{T}$, т'], [д, д'], [н, н'], [с, с'], [3, з'], [ц, ц'], [дз, дз'], [л, л'] and alveolar - [н, н'], [p, p'].
In prepalatal group are [ш], [ж], [ч], [дж ] as well as [й], which due to its peculiar features is viewed separately.

The group of velar consonants is comprised of: $\left[\kappa, \kappa^{\prime}\right],\left[\Gamma, \Gamma^{\prime}\right],\left[\mathrm{x}, \mathrm{x}^{\prime}\right]$.

Depending on looseness or elevation of the soft palate tip consonants form the group of nasals [M, M'], [H, H'] and oral - the rest of the consonants.

Another significant attribute is the way of articulation which determines the differentiation of consonants in the following groups:

-plosive - [п, п,'], [т, т'], [к, к'], [б, б’], д, д’], $\left[\Gamma, \Gamma^{\prime}\right]$

-affricate - [ц, ц'], [дз, дз'], [ч], [дж]

-fricative - [ф, ф'], [в, в'], [c, c'], [3, 3’], [ж, ж'], [x, x']

-nasal - [м, м'], [н, н']

-lateral - [л, л']

-trill $-[\mathrm{p}]$

-glide $-[\breve{и ̆}]$

\section{Consonant sounds and visual perception}

Perception of consonants through auditory modality is in direct relation with stress fixed upon one or other adjacent vowels. Perception is successful when stress is on following vowel sound. Transferring stress to preceding vocal changes the perception process in a negative way.

In visual perception of consonants stress position has analogical function.

In existing practice of training people with hearing impairment in the ability to "register on lips" opinion is shared that consonants, representing the group of bilabials $[\Pi, \sigma, м],[\Pi$, б' M'] $^{\prime}$, labiodentals [ф, в], [ф', в' '] and post alveolar $[ш],[ж],[ч],[щ]$ follow the right visual perception model in $100 \%$ of the cases $(10,11)$. These two groups of sounds are united in such optical principle in which they do not resemble sounds from other phonetic classes.

Optical attributes of belonging to the group of tongue - pre-palatal consonants are not perceived in all of the cases due to the accommodation principle and under its influence certain consonant sounds (from other phonetic groups) are labialized and acquire in these conditions visual resemblance to tongue prepalatal consonants.

An important moment is directing attention to existing potential for differentiation through 
sight of the attributes of consonants' palatality and nonpalatality. In Bulgarian language, depending on these distinguishing properties, sounds are divided in two big phonetic groups.

In relation to the different sound groups differentiation of the attributes hardness and softness occurs in different aspect. Palatalization is a result from slight elevation of the middle part of the tongue toward palate.

Main differential feature, besides the change of tongue localization is the drawing of lips to a rear position.

From the group of bilabial consonants $[п, б, м]$, [ח', б', м'], in the position of best visibility comes the sound $[\mathbf{I}]$, which takes the role of universal replacement. The remaining consonants are perceived visually in the following order: [м], [п '], [м'],[б], [б’].

Identical peculiarity is registered in perception of labiodental consonants $[\phi, \mathrm{B}],[\phi ', \mathrm{~B}$ ' $]$. Sound [\$] carries out its function of a universal substitute in relation to the rest of the consonants from the group.

The characteristics of the visual perception of post - alveolar consonants [ш, ж, ч, щ] are in accordance with the bilabial and labiodental consonant sounds. Main substitute in this phonetic group is the consonant [III].

In the group of alveodental sibilant sounds [c],[3], [ц], [c'], [3'] from the parallel drawn between the other sounds $[c]$ takes the first position for actualization and acquires quality of main substitute.

In the visual perception of alveodental plosive and affricate consonants [т], [д], [н], [л], [т'], [д'], [н'], [л'] as the main substitute is distinguished [T] (in perception of non-palatal consonants д, н, л) and regarding palatal [т'], [д'], [н'] the role of substitute often takes consonant $[\mathbf{c}]$.

Palatal consonants as a rule are replaced by their corresponding non-palatal ones in the pair.

Palatal consonant [л] is replaced mainly by nonpalatal [p].

The opposite phenomenon is observed in trills $\left[\mathrm{p}, \mathrm{p}^{\prime}\right]$. Palatal $[\mathrm{p}]$ is reproduced in more rare cases compared to non-palatal [p].

From the group of velar consonants $[\kappa, \Gamma, \mathrm{x}]$ which lack distinguishing optical features, actualization in extremely rare cases receives sound $[\boldsymbol{\kappa}]$, which is also a the main substitute for consonants $[\Gamma][\mathrm{x}]$.

\section{Word stress and visual perception}

It is known from phonetics and phonology that the main components called suprasegments, which serve to construct prosodic system are three: loudness, pitch and duration. They are specified correspondingly in intensity, frequency and continuance. They characterize the main tone of speech units.

Interrelations, changes and relations of acoustic components determine stress and intonation part of the prosodic speech phenomena.

Word stress differentiates word from phrase and has organizing role in relation to word.

This prosodic unit not only distinguishes words from the whole grammatical structure, but it also places their separate syllables in more different conditions. It is accepted such a syllable to be called stressed. The optical characteristics of a stressed syllable are clearer and more distinct.

Word stress in Bulgarian language has a number of features. Its mobility and flexibility is an important detail. Mobility is expressed in its ability to be fixed in different in their order syllables in the beginning and the end of different words (дърво, праскова, портокал).

In transformation of the word forms Bulgarian stress is able to move from one syllable to another, from one morpheme to another (коляно-колена; семе-семена).

The character of vocals' articulation is defined by localization of stress, and they are more or less reduced in syllables without stress. Harmonizing with the number of syllables, stress adds to word certain rhythmic shape.

Stress has also a sense-distinguishing function (nара-nара), it defines word form (носи-носи). Changes in intensity and duration of pronunciation related to the separation of the syllable under stress and the reduction of the unstressed ones define the articulation intensity, which manifests itself with a clear distinction and fullness of production of the sounds comprising the stressed syllable. This is more or less accessible to visual observation.

Certain difficulties in word stress localization are registered in children without hearing functions impairment during period when they become 
literate in cases when it is fixed upon vowels with less acoustic power.

Children with hearing loss, even when there is a substantial remaining hearing, come across difficulties in differentiating the stressed syllable in these conditions, especially if this stress is on vowel [и] regardless of the use of sound amplifying devices.

It is a well-known fact that children who lack practical experience in auditory perception of speech do not have the competence to compare the loudness of vocal - under stress in the specific word, with the same loudness, but in different words and without stress. The consequence is that children consider a syllable stressed when it is separated by its intensity of sound from the other syllables within the same word.

The perception of stress through optical sensory channel is analogical. The circumstance which creates difficulties (the different acoustic power of vowels in the process of auditory perception) in visual perception is the difference in amplitudes of lips and mandible movement.

Important condition for visual perception of stress is not only the amplitude of articulatory organs' movement. The degree of expression of different vowels in the process of their articulation is of significant importance. Word stress possesses good optical expression when it is placed on wide vowels, with bright characteristic articulation.

Specifics which go with visual perception of word stress are of significant importance for therapeutic approaches of specialists toward trainees in the ability to "register".

One of the main elements of word stress is the stressed syllable pronunciation duration. Its emphasizing (longer continuation) in pronunciation stimulates visual perception. The degree of (stressed) vowel sound emphasis may reach extent to which its pronunciation can be longer than the pronunciation of vocals constituting the given word.

Moderation in accentuating word stress of specialists in their own speech makes it more immediate, smooth and rhythmic. The natural verbal example of rehabilitation therapists is extremely important for the visual perception of word stress by children.
Visual perception of word stress is determined by the state of the habit to "register". "Catching" the rhythmic shape of different sound combinations, the exact and precise perception of its dynamics is related to the high development level of "speechreading" ability.

\section{Logical (phrasal) stress and visual perception}

The third element constituting phonetic system of language, complex in its structure and not enough explored yet, is intonation.

Intonation is generally regarded as a prosodic subsystem. It is one of the extremely important suprasegment features of speech. On the basis of intonation lie dynamic, temporal, melodic characteristics and pauses, combinations of which compose the phonetic structure.

Intonation is viewed as an important tool for the segmentation of speech in phrases, and phrases to smaller rhythmic-melodic and meaningful units - syntagms. Dynamic and temporal elements in phrase outline the contours of the socalled phrasal stress.

Phrasal (logical) stress is defined by D. Tilkov and T. Boyadjiev (8) as "intonational predominance of a speech segment - a separated word or a group of words".

In the pronunciation of some phrases, the meaning of certain words is not stressed and they are produced with no logical focus. The more meaningful significance is ascribed to a word or group of words, the greater their potential is in terms of force, duration and intensity.

Phrasal stress does not change the location of the word stress but "is superimposed over the word stress" (8) because by using the physical components (intensity, duration and frequency of the basic tone) the syllable stress is emphasized and the accent on it is greater.

Regularities in the visual perception of logical stress are similar to those of the perception of the word stress. The same phonetic means underlie both types of stress: the change of the voice volume and the duration of pronunciation. The logical stress in the flow of speech is also removed through the melodic means. Breaks whose intention is connected with the need for relatively independent in terms of meaning parts in the flow of speech to be separated are in a position of access to vision (9).

Changes in the intensity and duration of sound that distinguish the word and the logical stress 
are an integral part of certain changes that occur in the intensity of articulation. These amplitude movements provide access to the visual modality.

\section{CONCLUSION}

Visual perception and understanding spoken language is a process linked to the interpretation of coded information from the communicator. This implies intensive visual observation of oral movements, complemented by all paralinguistic and extra linguistic elements, situationallyoriented signs, verbal context.

"Reading Speech" is a skill presented by some authors as an "intuitive ability", which interacts with linguistic competence, durable intrinsic motivation, persistent self-control, the ability to predict linguistic forecast.

The visual perception of speech is an important addition to the perception by the auditory modality, but does not act as its substitute. Undoubtedly, the degree of hearing loss determines the individual needs of the activation of the sensory basis of visual processing.

Knowledge of the sensor basis of the "reading of speech" on a global scale, the mechanisms for perception and processing of the incoming information are extremely important for the implementation of effective educational and therapeutic models for children with limited functioning of the auditory modality.

\section{REFERENCES}

1. Ewing I. Lip reading and hearing aids. Manchester, 1959.

2. Conrad, R. Lip-reading by deaf and hearing children. The British journal of education psychology Volume: 47 Issue: 1, 1977-Feb

3. Kaplan, H., Bally, S \& Garretson C. A Way to Improve Understanding, $\left(2^{\text {nd }}\right.$ edition, revised), Washington. 1995.

4. Campbell, Ruth. Speechreading and the Bruce-Young model of face recognition: Early findings and recent developments British Journal of Psychology Volume: 102 Special Issue: SI, 704-710 Part: 4, 2011.

5. Levterova D. Visual perception and understanding of spoken language in persons with hearing impairments. Sofia, 2003.

6. Matte A. \& Nikitina N. Visual Perception of oral speech. Moscow. 1974.

7. Zuikov, S.A. Methodology for linguistic training of deaf children. M., "Enlightenment", 1977

8. Tilkov, D., T. Boyadzhiev. Bulgarian phonetics. Science and Art, Sofia, 1977.

9. Katzarska, V.Methodology for forming spoken language in children with hearing disorders, Pronunciation, Blagoevgrad, 2001.

10. Alyakrinskii, V. V. Visionary perception of oral speech with normal or impaired auditory functions. L., „Nauka”, 1979.

11. Mironova, E.V. Evaluation of the habit of reading by the lips. M., 1980. 